\title{
Performance of a universal PCR assay to identify different Leishmania species causative of Old World cutaneous leishmaniasis
}

\author{
Mahmoud Nateghi Rostami ${ }^{*}$, Fatemeh Darzi ${ }^{1}$, Mahin Farahmand ${ }^{1}$, Mohsen Aghaei $^{2}$ and Parviz Parvizi ${ }^{3}$
}

\begin{abstract}
Background: The characterization of Leishmania species is important for clinical management of the diseases and the epidemiological control of the parasite distribution. Most of the published polymerase chain reaction (PCR) amplification methods lack the ability to identify all species complexes, have low performance and usually need post-PCR procedures. There is a need for improving the diagnosis of $C L$ by development of an accurate affordable PCR method to identify all Leishmania species in clinical specimens.
\end{abstract}

Methods: We designed an optimized a PCR amplifying the internal transcribed spacer 2 sequence of the ribosomal RNA gene (ITS2) aligned from different strains of CL-causing Leishmania species in the Old World. The performance of the method was evaluated on lesion samples from several CL suspected patients and the limit of detection (LOD) was determined on DNA of promastigotes from reference strains.

Results: The universal PCR enabled simultaneous discrimination of L. major, L. tropica and L. infantum using one primer pair in one reaction. Stained smear microscopy and Novy-MacNeal-Nicolle (NNN) medium culture alone detected $77.27 \%$ (17/22) and $72.73 \%$ (16/22) of the positive CL samples, respectively. The PCR assay showed 100\% sensitivity (22/22) (95\% Cl: 84.56-100\%) and 100\% specificity (3/3) (95\% Cl: 29.24-100\%) for species identification on isolates from lesion scraping/exudate and 100\% sensitivity (13/13) (95\% Cl: 75.29-100\%) and 100\% specificity (11/11) ( $95 \%$ Cl: $71.51-100 \%$ ) for species identification on biopsy samples of $\mathrm{CL}$ patients, while being capable to successfully amplify as little as $0.01-0.1 \mathrm{pg}$ of Leishmania DNA from cultured promastigotes.

Conclusions: We present a validated easy-to-use affordable universal PCR assay to identify the most common Old World Leishmania species causing CL. This PCR assay could be used as a sensitive/specific technique to diagnose CLcausing Leishmania species in clinical samples with high accuracy.

Keywords: Leishmania, PCR, ITS, Diagnosis, Cutaneous leishmaniasis

\section{Background}

Cutaneous leishmaniasis $(\mathrm{CL})$ is usually manifested as a nodule which gradually develops to a self-healing lesion leaving a scar, but a polymorphism is seen in lesion characteristics, and diverse atypical forms are reported [1].

*Correspondence: m_nateghi@pasteur.ac.ir

${ }^{1}$ Laboratory of Host-Parasite Interactions, Department of Parasitology, Pasteur Institute of Iran, Tehran, Iran

Full list of author information is available at the end of the article
The host's immune response, Leishmania species, and inter- and intra-species genetic diversity of Leishmania might be involved in this clinical polymorphism [2, 3]. CL is a geographically extensive disease and in the Old World can be caused by any of the four different species: Leishmania major causing self-healing zoonotic CL (ZCL); $L$. tropica causing anthroponotic CL (ACL); L. infantum principally a VL-causing species which cause CL; and $L$. aethiopica causing $\mathrm{CL}$ which is limited in distribution in the African region $[1,4,5]$. CL due to L. infantum is a

c) The Author(s) 2020. This article is licensed under a Creative Commons Attribution 4.0 International License, which permits use, sharing, adaptation, distribution and reproduction in any medium or format, as long as you give appropriate credit to the original author(s) and the source, provide a link to the Creative Commons licence, and indicate if changes were made. The images or other third party material in this article are included in the article's Creative Commons licence, unless indicated otherwise in a credit line to the material. If material is not included in the article's Creative Commons licence and your intended use is not permitted by statutory regulation or exceeds the permitted use, you will need to obtain permission directly from the copyright holder. To view a copy of this licence, visit http://creativeco mmons.org/licenses/by/4.0/. The Creative Commons Public Domain Dedication waiver (http://creativecommons.org/publicdomain/ zero/1.0/) applies to the data made available in this article, unless otherwise stated in a credit line to the data. 
sporadic disease in Asia and the Middle East where the main causes of CL are L. major and L. tropica. However, $L$. infantum $\mathrm{CL}$ is more frequently present in the Mediterranean Basin area including countries of North Africa and southwestern Europe. Also, in the Americas there is increasing evidence that CL due to L. chagasi (identical to $L$. infantum) is present, although it is more associated with VL [6].

During the last few decades, CL has geographically been extended beyond the areas where it was previously recorded [5]. The presence of multiple Leishmania species with overlapping clinical features that sometimes leads to misdiagnosis in endemic areas [7], as well as the genetic heterogeneity of the parasite $[8,9]$, accentuate requirement for development of laboratory tests with high accuracy to be used for species identification of Leishmania spp. [10]. However, conventional parasitology methods have an intermediate diagnostic sensitivity on dermal aspirate samples of CL, as they are influenced by the sampling procedure, type of skin lesion, parasite load and technical personnel expertise [11]. Molecular methods based upon the polymerase chain reaction (PCR) amplification of Leishmania DNA have been widespread for diagnosis of the causative species of CL [1215]. Many such PCR assays have been reported in the literature, but most of the PCR amplification protocols have low accuracy to identify all species complexes, have no validity testing on clinical samples and some of them need post-PCR procedures such as sequencing, restriction digestion or melting curve analysis, which are not readily available in remote locations $[16,17]$.

PCR amplifications targeting the kinetoplast and ribosomal RNA genes are amongst the most commonly used approach for the diagnosis and/or identification of Leishmania species [18], and the internal transcribed spacer region of the ribosomal DNA repeat unit (ITS2) has previously been exploited for Old World Leishmania species discrimination $[19,20]$. In most eukaryotic organisms, genes encoding $18 \mathrm{~S}, 5.8 \mathrm{~S}$, and $28 \mathrm{~S}$ rRNA are organized as tandem repeats which are transcribed together, generating a long primary transcript. $5^{\prime}$ and $3^{\prime}$ external transcribed spacers (ETSs) and internal transcribed spacers (ITSs) are removed from the primary transcript by snoRNAs and multiple enzymes [21]. The L. major genome contains only $\sim 12$ copies of the rRNA gene repeat per haploid genome, organized in tandem arrays on chromosome 27 [22]. Due to the lack of whole genome sequencing data, the copy number of rRNA gene clusters is not clearly available for $L$. tropica and $L$. aethiopica species. Regarding $L$. infantum, analysis of available bioinformatics databases shows that different subunits of the rRNA gene are located in different chromosomes and are not arranged in a head-to-tail tandem array. The number of
rRNA gene sets in another VL causing species (L. donovani haploid genome) is reported to be 166 [23].

The aim of the present study was to design a universal PCR method based on the ITS rDNA region to identify parasite species directly from clinical samples or Leishmania isolates. It is estimated that several copies of rRNA gene repeats exist in the diploid genome of different Leishmania species, ranging from 20 to more than 150, which makes it a good target for analyzing low parasite quantities $[23,24]$. In this study, we describe a universal PCR based on ITS2 rDNA for the discrimination of L. tropica, L. major and L. infantum by using one pair of primers. Identification of more than one agent in one reaction is more cost-effective, more rapid, and more acceptable for the patients. We show the validation of our results on clinical samples from CL patients.

\section{Methods}

Study population, ethical considerations and sampling

Patients with clinical manifestations compatible with active CL who were referred to known centers for diagnosis of CL were included. The same samples which were collected during routine diagnostics were used; however, informed consent was obtained from each volunteer who participated in the study. After examination of each volunteer by a dermatologist, demographic data, history and clinical signs/symptoms were recorded in a questionnaire. The skin was sterilized, and exudates were obtained from the suspected lesion border. For non-ulcerated lesions (nodules, papules or plaques) lesion scrapings were taken from the incision by a sterile scalpel.

In the clinical validation assay, a total of 49 patients were included in the study. Twenty-five lesion scraping/exudate samples were collected from CL suspected patients with different typical/atypical forms of the disease. Also, 24 fresh biopsies from skin lesions that mimic CL were taken.

Three reference strains of Leishmania, including $L$. major MRHO/IR/75/ER, L. tropica MHOM/SU/74/ K27 and L. infantum MCAN/IR/96/LON49, were used as positive controls along with samples for PCR assay. Four reference strains of $L$. major including $\mathrm{MRHO} /$ IR/75/ER, MHOM/IL/81/Friedlin, MHOM/SU/73/5ASKH and MHOM/IR/2018/Q-MN, three reference strains of $L$. tropica including MHOM/IR/02/Mash10, MHOM/SU/74/K27 and MHOM/IR/2017/IPI, two reference strains of $L$. infantum including MCAN/IR/96/ LON49 and MHOM/TN/80/IPT1 were used for LOD determination.

\section{Direct examination of stained smears}

The lesion samples were smeared onto glass slides, airdried, fixed with absolute methanol and stained with 
Giemsa. The slides were examined with a $40 \times$ and $100 \times$ immersion objectives under light microscope for the presence of amastigote forms at least $30 \mathrm{~min}$ before reporting the final result.

\section{Parasite culture}

Part of the dermal exudate was inoculated under sterile conditions into the Novy-MacNeal-Nicolle (NNN) medium (Pasteur Institute, Tehran, Iran) overlaid with RPMI 1640 (Gibco Invitrogen, Carlsbad, CA, USA), incubated at $18-24{ }^{\circ} \mathrm{C}$ and the liquid phase was examined for parasite growth by light microscopy every other day for 6 weeks [25].

\section{DNA extraction}

Additional lesion samples were taken and transferred to $2 \mathrm{ml}$ vials containing sterile phosphate-buffered saline (PBS, pH 7.2) and used for DNA extraction. DNA extraction was carried out on each the lesion sample, culture isolates and Leishmania spp. reference strains using the QIAamp DNA Mini Kit (Qiagen, Hilden, Germany) which provides silica-membrane-based nucleic acid purification according to manufacturer's instructions. DNA concentration and purity were estimated by measuring the absorbance at $260 \mathrm{~nm}$ and $280 \mathrm{~nm}$ using a NanoDrop one spectrophotometer (Thermo Fisher Scientific, Waltham, MA, USA). The DNA was kept at $-20{ }^{\circ} \mathrm{C}$ until further use.

\section{PCR assay set-up}

Several primer sets were designed for the ITS region of the rRNA gene and those with acceptable physicochemical parameters were selected and aligned with the sequences from the databases using the nucleotide Basic Local Alignment Search Tool (BLASTn). BLASTn analysis enabled us to screen for possible non-specific interactions with other organisms or off-target amplification. BioEdit sequence alignment editor ver. 7.0.5.3 software (https://www.bioedit.com) and MEGA version 7.0.26 software [26] were used to align sequences of the ITS region from different strains of Leishmania to identify conserved and polymorphic regions for designing specific primers. The specific primer pairs which amplified the ITS2 region of different species of Leishmania with discriminating amplicon sizes, were selected.

PCR reactions were conducted in a total volume of 25 $\mu \mathrm{l}$, containing $2 \times$ PCR buffer, containing Tris $-\mathrm{HCl} \mathrm{pH}$ 8.5, $0.2 \%$ Tween $20,3 \mathrm{mM} \mathrm{MgCl}_{2}, 0.4 \mathrm{mM}$ of each dNTP, $0.2 \mathrm{u} / \mu \mathrm{l}$ Ampliqon Taq DNA polymerase (Ampliqon, Odense, Denmark) and red dye for tracking. In addition, $0.2-0.5 \mu \mathrm{M}$ of each specific primer pair UNIL-IR-P and UNIL-IR-M was used (Table 1). The DNA template concentrations were adjusted to a range of $0.01-100 \mathrm{pg} /$ $\mu \mathrm{l}$ depending on the reaction. Annealing temperatures ranging between $54-62{ }^{\circ} \mathrm{C}$ were tested, and after several adjustments the temperature was optimized at $57.0{ }^{\circ} \mathrm{C}$. Cycling conditions were as follows: initial denaturation $95{ }^{\circ} \mathrm{C}$ for $5 \mathrm{~min}$; followed by 30 cycles of $95{ }^{\circ} \mathrm{C}$ for $30 \mathrm{~s}$, $57{ }^{\circ} \mathrm{C}$ for $45 \mathrm{~s}, 72{ }^{\circ} \mathrm{C}$ for $45 \mathrm{~s}$ and a final extension step at $72{ }^{\circ} \mathrm{C}$ for $5 \mathrm{~min}$. The amplified products were electrophoresed on $1.5 \%$ agarose gels in $1 \times$ Tris-acetate-EDTA (TAE) buffer. After performing electrophoresis, for DNA visualization, gels were stained with a 1:5000 dilution of the sensitive Eco-Stain Plus (Bio Basic Inc., Markham ON, Canada) in TAE buffer for $30 \mathrm{~min}$. The results were visualized under UV light by using a Gel-Doc instrument (Vilber Lourmat, Collégien, France). The resolution of the images was improved for best quality results. The PCR conditions were optimized for each assay by using DNA from the three reference strains of Leishmania ( $L$. major $\mathrm{MRHO} / \mathrm{IR} / 75 / \mathrm{ER}$, L. tropica $\mathrm{MHOM} / \mathrm{SU} / 74 / \mathrm{K} 27$ and $L$. infantum MCAN/IR/96/LON49). The non-template negative controls (NTCs) were included for contamination control. Since the amplicons did not differ significantly in size, to confirm the results in uncertain cases a multiplex PCR assay was performed in the same

Table 1 Characteristics of PCR primer pairs

\begin{tabular}{|c|c|c|c|c|c|c|c|}
\hline \multirow[t]{2}{*}{ Strategy } & \multirow[t]{2}{*}{ Name } & \multirow[t]{2}{*}{ Species } & \multicolumn{2}{|l|}{ Primer sequence $\left(5^{\prime}-3^{\prime}\right)$} & \multirow[t]{2}{*}{ GenBank ID } & \multirow[t]{2}{*}{ Nucleotide no. } & \multirow[t]{2}{*}{ Size (bp) } \\
\hline & & & Forward & Reverse & & & \\
\hline \multirow[t]{3}{*}{ Multiplex PCR } & $\begin{array}{l}\text { MULt-IR-P and MULt- } \\
\text { IR-M }\end{array}$ & L. tropica & $\begin{array}{l}\text { ACGCACCGCCTATAC } \\
\text { ACAAA }\end{array}$ & $\begin{array}{l}\text { ACTACTGCGTTCTTC } \\
\text { ACCGA }\end{array}$ & MH627386.1 & $138-292$ & 155 \\
\hline & $\begin{array}{l}\text { MULm-IR-P and } \\
\text { MULm-IR-M }\end{array}$ & L. major & $\begin{array}{l}\text { TCCGATGCTTACACC } \\
\text { CCAAA }\end{array}$ & $\begin{array}{l}\text { ATGCACGGGGATGAC } \\
\text { ACAAT }\end{array}$ & KU680845.1 & $16-421$ & 406 \\
\hline & $\begin{array}{l}\text { MULi-IR-P and MULi- } \\
\text { IR-M }\end{array}$ & L. infantum & $\begin{array}{l}\text { ACATATACAACTCGG } \\
\text { GGAGACC }\end{array}$ & $\begin{array}{l}\text { AGGAAGCCAAGTCAT } \\
\text { CCATCG }\end{array}$ & KU975159.1 & $34-274$ & 241 \\
\hline Universal PCR & $\begin{array}{l}\text { UNIL-IR-P and UNIL- } \\
\text { IR-M }\end{array}$ & $\begin{array}{l}\text { L. major, L. } \\
\text { tropica, L. } \\
\text { infantum }\end{array}$ & $\begin{array}{l}\text { CATGCCATATTCTCA } \\
\text { GTGTCG }\end{array}$ & $\begin{array}{l}\text { GGTCTGTAAACAAAG } \\
\text { GTTGTCG }\end{array}$ & - & - & $\begin{array}{l}\text { L. m: } 740 ; L . \\
\quad \text { inf: } 690 ; L \text {. } \\
\quad t: 640\end{array}$ \\
\hline
\end{tabular}


tube using different primer pairs (Table 1) targeting kinetoplast DNA. Multiplex PCR conditions were established by using a mixture of DNA from all 3 Leishmania species. The $25 \mu \mathrm{l}$ PCR reaction mixture consisted of Tris$\mathrm{HCl}$; pH 8.8, 0.01\% Tween-20, $3 \mathrm{mM} \mathrm{MgCl} 2,0.5 \mathrm{mM}$ each dNTPs, 3 U Taq DNA polymerase (Invitrogen, Carlsbad, CA, USA) and $0.5 \mu \mathrm{M}$ of each of the three specific primer pairs. Cycling conditions were the same as above.

To avoid DNA contamination, different steps of the technical procedures were carried out in separate areas with dedicated consumables and decontamination. In lesion samples, the presence of possible PCR reaction inhibitors was ascertained by testing with specific primers for the $\beta$-actin gene. Some PCR products were subjected to sequencing for confirmation of correct amplification of the target.

\section{Optimization and limit of detection (LOD) determination}

Following the development of the PCR protocols, to determine the LOD of the universal PCR for each species, DNA was extracted from promastigotes of 4 reference strains of $L$. major, 3 reference strains of $L$. tropica and 2 reference strains of L. infantum. To evaluate the possible interference of host DNAs, 30 ng of DNA purified from human skin cells were added to each dilution [27]. To determine LODs, 10 -fold serially diluted concentrations including 100,10,1, 0.1, and $0.01 \mathrm{pg}$ of parasite DNAs were spiked into the reactions then the PCR was performed with the same cycling program. The different possible combinations of the three species were also regarded and included in the PCR schedule. A total of 101 PCR reactions were performed along with NTCs.

\section{Validation with clinical specimens Lesion scraping/exudate}

Once the PCR conditions were optimized, the validity of identifying the correct species from clinical samples was assessed on skin lesions of CL patients caused by $L$. major or L. tropica. Lesion samples were subjected to universal PCR assay using c.10 ng of DNA per reaction. This amount of DNA was potentially a mixture of parasite and lesion cells naturally including the dermal/ epidermal layer, infiltrated immune cells, bacterial flora and other local cells.

\section{Fresh lesion biopsy}

The validity of the universal PCR assay was tested with the biopsy samples obtained in sterile PBS from patients suffering from different cutaneous diseases which mimic $\mathrm{CL}$, including fungal skin infections, lupus erythematosus, leprosy, skin neoplasm and tuberculosis.

\section{Performance of the test}

For determining the performance of the universal PCR and to consider a case positive for $\mathrm{CL}$, a combination of two molecular methods including a nested-PCR assay followed by RFLP using Rapid Digest MnlI (Thermo Fisher Scientific, USA) was considered as reference (gold) standard [28] (see Additional file 1: Figure S1). Since this is a diagnostic test accuracy (DTA) study, a reference standard method was used to perfectly discriminate between participants with or without CL conditions and to provide unbiased estimates of the diagnostic accuracy measure of the index test (universal PCR). The authors were blinded of the result of testing on patients with skin lesions suggestive of CL. The gold standard method and universal PCR were made simultaneously on the same sample for each patient that was supposed to be included in the study; and the authors were not aware of the cases of $C L$ while testing universal PCR.

In evaluation of universal PCR on lesion scraping/exudate samples, a positive result for one of conventional methods (smear or culture) was also considered. Sensitivity, specificity, positive predictive values (PPV), negative predictive values (NPV), and Cohen's kappa measure of agreement $(\kappa)$ were determined. The strength of agreement was defined as follows: poor $(\kappa<0.20)$; fair $(\kappa$ of $0.21-0.40$ ); moderate ( $\mathrm{k}$ of $0.41-0.60$ ); good ( $\mathrm{k}$ of $0.61-$ 0.80 ); and very good ( $\mathrm{k}$ of $0.81-1.00$ ).

For the purpose of implementation in clinical settings of other laboratories, a few of either primer pairs alone or together with clinical specimens were submitted to three other centers of endemic area in Iran, where PCR mixes were produced locally and the tests were performed by different persons. The DNA was provided from either the same samples or was extracted from the samples of local CL patients referred for diagnostic purposes.

\section{Results \\ Optimization and evaluation}

The position of the universal primer pair related to the ITS2 region of the rRNA gene on chromosome 27 of $L$. major strain Friedlin is shown in Fig. 1. Also, sequence alignment of three CL causing species against Friedlin strain is included in Additional file 2: Alignment S1, showing the primer pair position and flanking sequences of ITS1, 5.8 S and ITS2 rDNA fragments.

The amplicons were successfully obtained on scraping/ exudate samples, fresh skin biopsy samples and promastigotes of reference strains as shown in Figs. 2, 3. During cycling set-up, in some instances weak non-specific products were also amplified at lower annealing temperatures which were then resolved at $57.0^{\circ} \mathrm{C}$. Figure 4 shows a representative result of multiplex PCR on samples. 


\section{Leishmania rRNA gene tandem repeats}

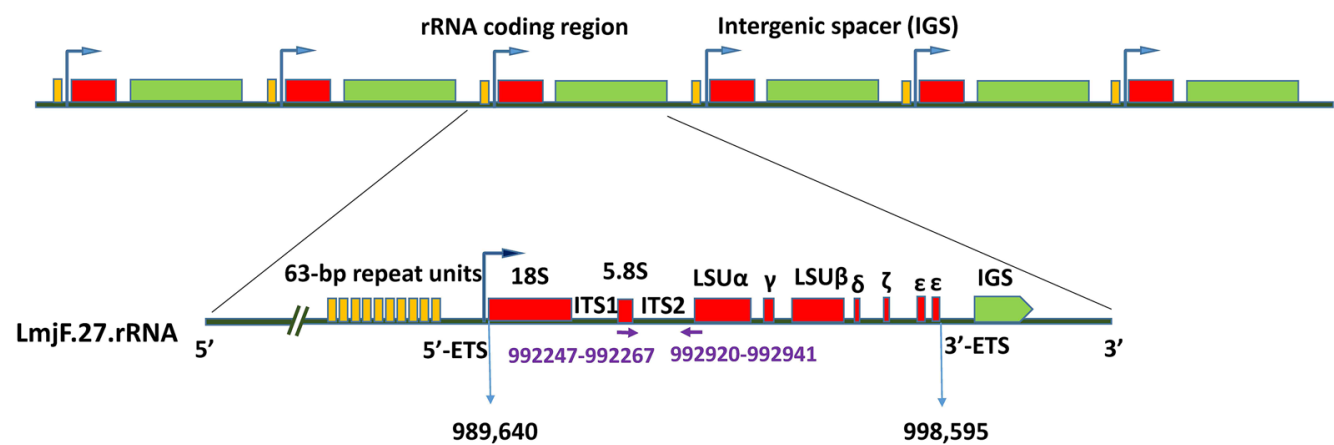

Fig. 1 Leishmania major rRNA gene tandem repeats and primer positions. rRNA gene fragments and position of the universal primer pair in relation to the nucleotide sequences of chromosome 27 of Leishmania major strain Friedlin (TriTrypDB accession number: LmjF.27.rRNA), drawn to scale. The 18S, ITS1, 5.8S, ITS2 and 285 units of rDNA are indicated. Small arrows show the forward and reverse primers. The start and end nucleotide of each primer are shown. Right angle arrows show transcription start sites. Abbreviations: LSU, large subunit; IGS, intergenic spacer; ETS, external transcribed spacer; ITS, internal transcribed spacer

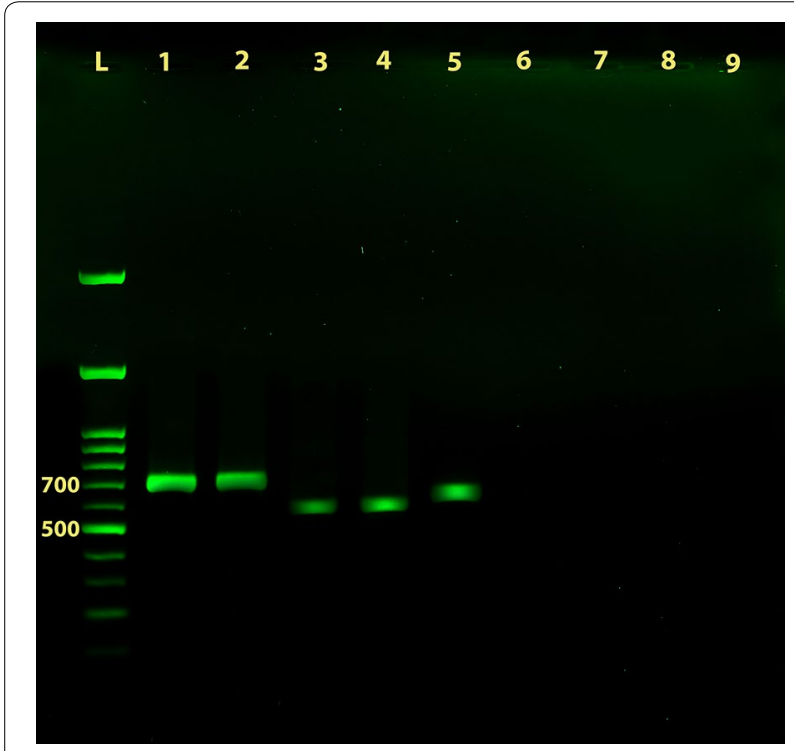

Fig. 2 Identification of Leishmania species from biopsy samples. PCR amplification of Leishmania genomic DNA from fresh biopsy samples using the newly developed universal primers UNIL-IR-P and UNIL-IR-M subjected to electrophoresis on a 1.5\% agarose gel. Lane 1: amplicon of $L$. major MRHO/IR/75/ER reference strain; Lane 2: amplicon of a positive L. major sample; Lane 3: amplicon of L. tropica MHOM/SU/74/ K27 reference strain; Lane 4: amplicon of a positive L. tropica sample; Lane 5: amplicon of L. infantum MCAN/IR/96/LON49 reference strain; Lanes 6-8: negative biopsy samples that mimic $\mathrm{CL}$, including fungal skin infection, tuberculosis and skin neoplasm, respectively. Lane 9: non-template negative control. Lane L: 100 bp DNA ladder

Sequencing results showed that the primer sets and the PCR approach efficiently amplify the ITS2 locus of the rRNA gene of Leishmania species. The newly generated ITS2 sequences were submitted to the GenBank database

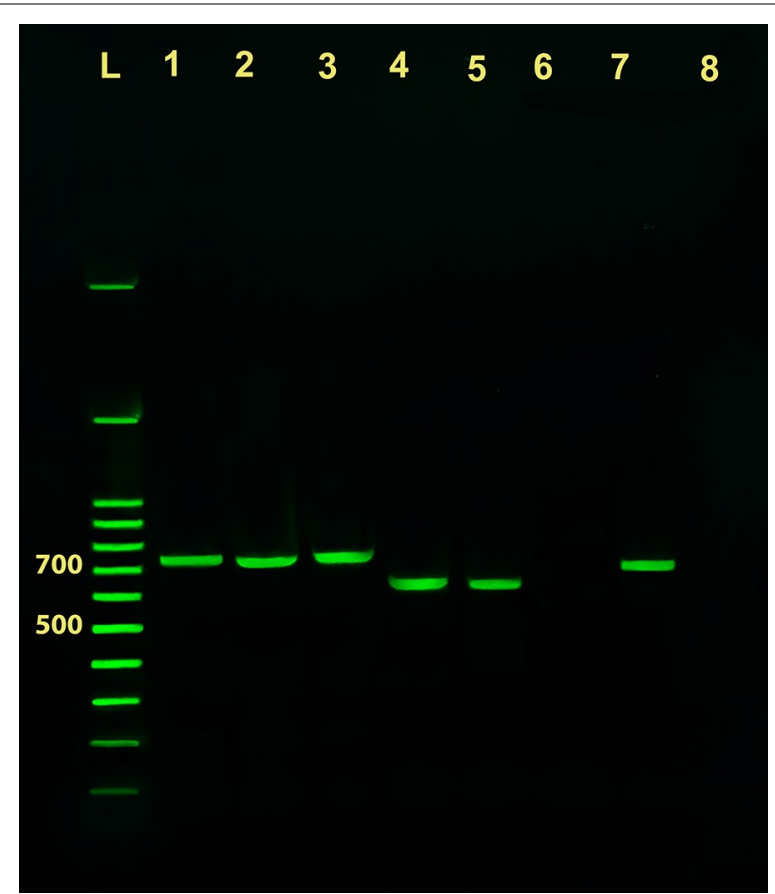

Fig. 3 Identification of Leishmania species from scraping/exudate clinical samples. PCR amplification of Leishmania genomic DNA from lesion scraping/exudate using the newly developed universal primers UNIL-IR-P and UNIL-IR-M subjected to electrophoresis on a 1.5\% agarose gel. Lane 1: amplicon of L. major MRHO/IR/75/ER reference strain; Lane 2: amplicon of L. major culture+/smear- samples; Lane 3: amplicon of L. major culture-/smear+ samples. Lane 4: amplicon of L. tropica MHOM/SU/74/K27 reference strain; Lane 5: amplicon of L. tropica culture+/smear+ samples; Lane 6: amplicon of culture-/smear-samples; Lane 7: amplicon of L. infantum MCAN/ IR/96/LON49 reference strain; Lane 8: non-template negative control. Lane L: 100 bp DNA ladder 


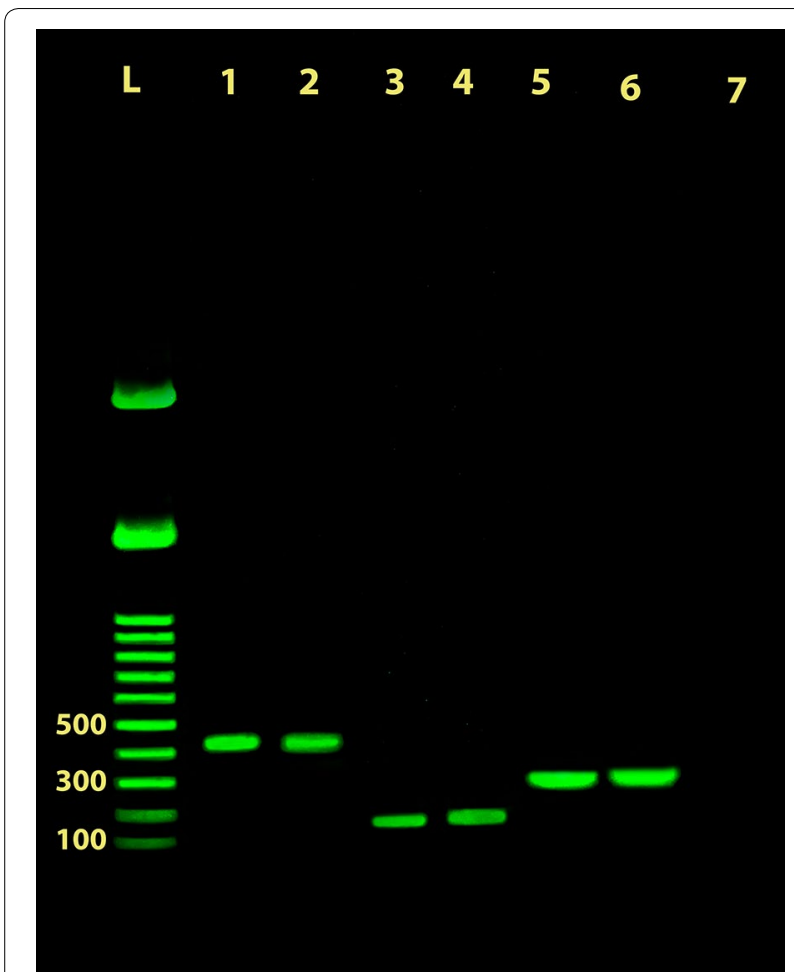

Fig. 4 Multiplex PCR amplification of Leishmania genomic DNA from lesion samples using the newly developed primer pairs subjected to electrophoresis on a 1.0\% agarose gel. Lane 1: amplicon of L. major MRHO/IR/75/ER reference strain; Lane 2: amplicon of a patient's L. major isolate. Lane 3: amplicon of L. tropica MHOM/SU/74/K27 reference strain; Lane 4: amplicon of a patient's $L$. tropica isolate; Lane 5: amplicon of L. infantum MCAN/IR/96/LON49 reference strain; Lane 6: amplicon of a patient's L. infantum isolate. Lane 7: non-template negative control. Lane L: 100 bp DNA ladder

under the accession numbers MN931857, MN931859 and MN969584.

This universal PCR was implemented successfully and validated for diagnosis of CL cases in three other laboratories of endemic area of Iran. No contamination of negative control was reported. In one CL-confirmed sample, the PCR tested negative but with increasing the amount of DNA the second PCR showed a positive result.

\section{LOD determination and applicability to culture promastigotes}

The universal PCR showed the potential to amplify as little as $0.01 \mathrm{pg}$ of DNA from promastigotes of L. major and $0.1 \mathrm{pg}$ of DNA from promastigotes of L. tropica and L. infantum, $0.1 \mathrm{pg}$ is about half a parasite's genome (Table 2). This detection limit was unaffected by the presence of DNA from other Leishmania species in a mixed reaction or by the presence of host DNAs (Fig. 5). For some DNA samples, the detection limit was higher, up to $1 \mathrm{pg}$; variations were probably caused by DNA degradation.

\section{Validation on clinical samples}

Tables 3 and 4 list the demographic and clinical information of the patient volunteers included in the study for blinded validation of the PCR on their lesion samples. In total, 25 scraping/exudate samples and 24 skin tissue biopsy samples were included in the validation assay, both using c.10 ng of DNA.

As shown in Table 3, patients had different clinical forms of $\mathrm{CL}$, such as sporotrichoid, disseminated and multiple lesions. Nearly $40.0 \%$ of the cases developed more than one lesion, with the hand as the most common site of lesion onset (52.0\%). The mean size ( \pm standard deviation, SD) of CL lesions was $22.6 \pm 14.18 \mathrm{~mm}$. Some patients received topical or systemic treatment which might influenced the test results. The mean age $( \pm$ SD) of the patients was $34.68 \pm 18.39$ years. Some patients had history of travel to endemic areas in Iran, Afghanistan or Iraq during the last 6 months before lesion onset.

Table 4 shows the main information of the CL suspected patients enrolled for diagnosis by fresh biopsy

Table 2 Result of universal PCR assay on serially diluted amount of DNA from promastigotes of Leishmania reference strains

\begin{tabular}{|c|c|c|c|c|c|c|}
\hline \multirow[t]{2}{*}{ Species } & \multicolumn{6}{|c|}{ Frequency of positive tests, $n(\%)$} \\
\hline & $100 \mathrm{pg} / \mu \mathrm{l}$ & $10 \mathrm{pg} / \mu \mathrm{l}$ & $1 \mathrm{pg} / \mu \mathrm{l}$ & $0.1 \mathrm{pg} / \mu \mathrm{l}$ & $0.01 \mathrm{pg} / \mu \mathrm{l}$ & NTC \\
\hline L. major $(n=4)$ & $4(100)$ & $45(100)$ & $4(100)$ & $4(100)$ & $4(100)$ & $0(0)$ \\
\hline L. tropica $(n=3)$ & $3(100)$ & $3(100)$ & $3(100)$ & $3(100)$ & $3(100)$ & $0(0)$ \\
\hline L. infantum $(n=2)$ & $2(100)$ & $2(100)$ & $2(100)$ & $2(100)$ & $0(0)$ & $0(0)$ \\
\hline L. major + L. tropica $(n=4)^{a}$ & $4(100)$ & $4(100)$ & $4(100)$ & $4(100)$ & $4(100)$ & $0(0)$ \\
\hline L. major + L. infantum $(n=3)^{a}$ & $3(100)$ & $3(100)$ & $3(100)$ & $3(100)$ & $0(0)$ & $0(0)$ \\
\hline L. tropica + L. infantum $(n=3)^{a}$ & $3(100)$ & $3(100)$ & $3(100)$ & $3(100)$ & $0(0)$ & $0(0)$ \\
\hline
\end{tabular}

a Presence of both bands of two species has been regarded as positive

Abbreviation: NTC: non-template control 


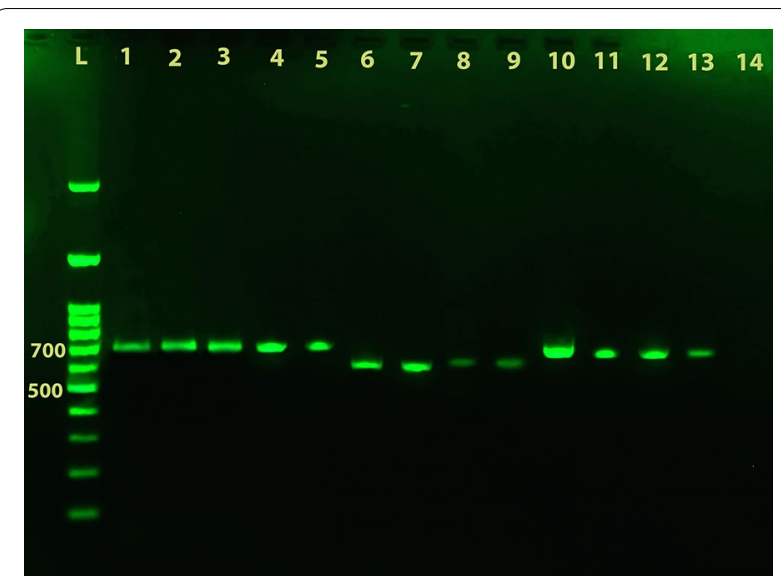

Fig. 5 LOD determination based on PCR amplification of serially diluted DNA from culture promastigotes of Leishmania parasites. DNA was extracted from culture promastigotes of different reference strains of L. major, L. tropica and L. infantum. Serially 10 -fold diluted amounts of 100,10,1, 0.1, and 0.01 pg of genomic DNAs were spiked into the reactions and the PCR amplification was performed as described with universal primers UNIL-IR-P and UNIL-IR-M. Human skin DNs were also added to each reaction for evaluation of possible interference. The different possible combinations of 3 species were also considered and included in the PCR schedule. PCR products were subjected to electrophoresis on a 1.5\% agarose gel. Lanes 1-5: L. major DNA with 100 to $0.01 \mathrm{pg} / \mu \mathrm{l}$ concentrations, respectively; Lanes 6-9: L. tropica DNA with 100 to $0.1 \mathrm{pg} / \mu \mathrm{l}$ concentrations, respectively; Lanes 10-13 L. infantum DNA with 100 to $0.1 \mathrm{pg} / \mu \mathrm{l}$ concentrations, respectively; Lane 14: non-template negative control. Lane L: 100 bp DNA ladder

sampling. The mean age $( \pm \mathrm{SD})$ of the patients was $41.46 \pm 22.29$ years. Hand was the most common site of lesion onset (37.5\%).

Figure 2 depicts one representative result of PCR assays on skin tissue biopsy samples and Fig. 3 depicts one representative result on scraping/exudate clinical samples. In samples containing L. major, occasionally, a weak PCR product was amplified in the assay, but this product showed a faint and smaller than $500 \mathrm{bp}$ amplicon which was clearly below the actual product size of $L$. major samples. No products were amplified using samples obtained from patients suffering from other skin diseases that mimic CL.

\section{Performance of the test}

The performance of universal PCR on scraping/exudate and skin biopsy samples are abbreviated in Table 5. Leishmania spp. were successfully identified in the various CL skin samples, as 22 of 22 scraping/exudate samples and 13 of 13 biopsy samples showed a positive Leishmania product of the correct size with this PCR assay. No false negative PCR reaction occurred and the sensitivity of the PCR on scraping/exudate specimens was 100\% (95\% confidence interval, CI: $84.56-100 \%)$, the same as that of the biopsy samples (95\% CI: 75.29-100\%). There was no false positive result and the specificity of PCR on scraping/exudate (95\% CI: 71.51-100\%) and biopsy (95\% CI: 29.24-100\%) samples was $100 \%$.

Smear microscopy and parasite culture alone detected $77.27 \%$ (95\% CI: 54.63-92.18\%) and 72.73\% (95\% CI: 49.78-89.27\%) of the positive CL specimens, respectively, while culture and microscopy together improved the overall sensitivity to more than $90 \%(21 / 22)$. The specificity of both conventional methods was $100 \%$ (95\% CI: 29.24-100\%).

The agreement between PCR and smear microscopy was moderate $(\kappa=0.45 ; P=0.007)$ and between PCR and culture was fair $(\kappa=0.39 ; P=0.014)$ and the overall agreement between the PCR and parasitological approaches was very good $(\kappa=0.83 ; P<0.0001)$, when the results of the parasitology tests were determined by considering both smear and culture results.

\section{Discussion}

Among different genetic markers used for Leishmania identification, kinetoplast DNA (kDNA) and the ITS region have been vastly used to detect the parasite in different biological samples [18, 20, 29-31]. While highly sensitive approaches for identifying particular Leishmania species have been described, if multiple Leishmania spp. need to be differentiated in a diagnostic laboratory, molecular approaches that require different PCR primers for each species have the potential for carryover contamination. Although strategies to minimize this potential risk have been developed, contamination has been observed even when strict protocols were followed [29]. Moreover, using multiple primers is not cost-effective, needs more materials for PCR reactions, and more time to set-up the procedure. Our goal was to develop a molecular approach for species level discrimination that requires only one pair of PCR primers. We focused on the ITS region: the rRNA internal spacers are subject to less evolutionary pressure and show more sequence divergence than the coding regions and have been proposed as targets for molecular typing. We designed species-specific primers flanking the ITS2 region adequate for our diagnostic goal to differentially identify Leishmania spp. causing CL. The substantial differences in the ITS2 region spanned by these primers are due to InDel and polymorphic loci of repeated motifs including microsatellite markers, typically with one to six non-coding nucleotides per repeated unit $[8,20]$. However, we did not access to samples positive for L. aethiopica to compare the sensitivity of the primer pairs.

The classical methods have limitations, especially with regard to sensitivity. In this study the sensitivity of either microscopy or parasite culture alone was 


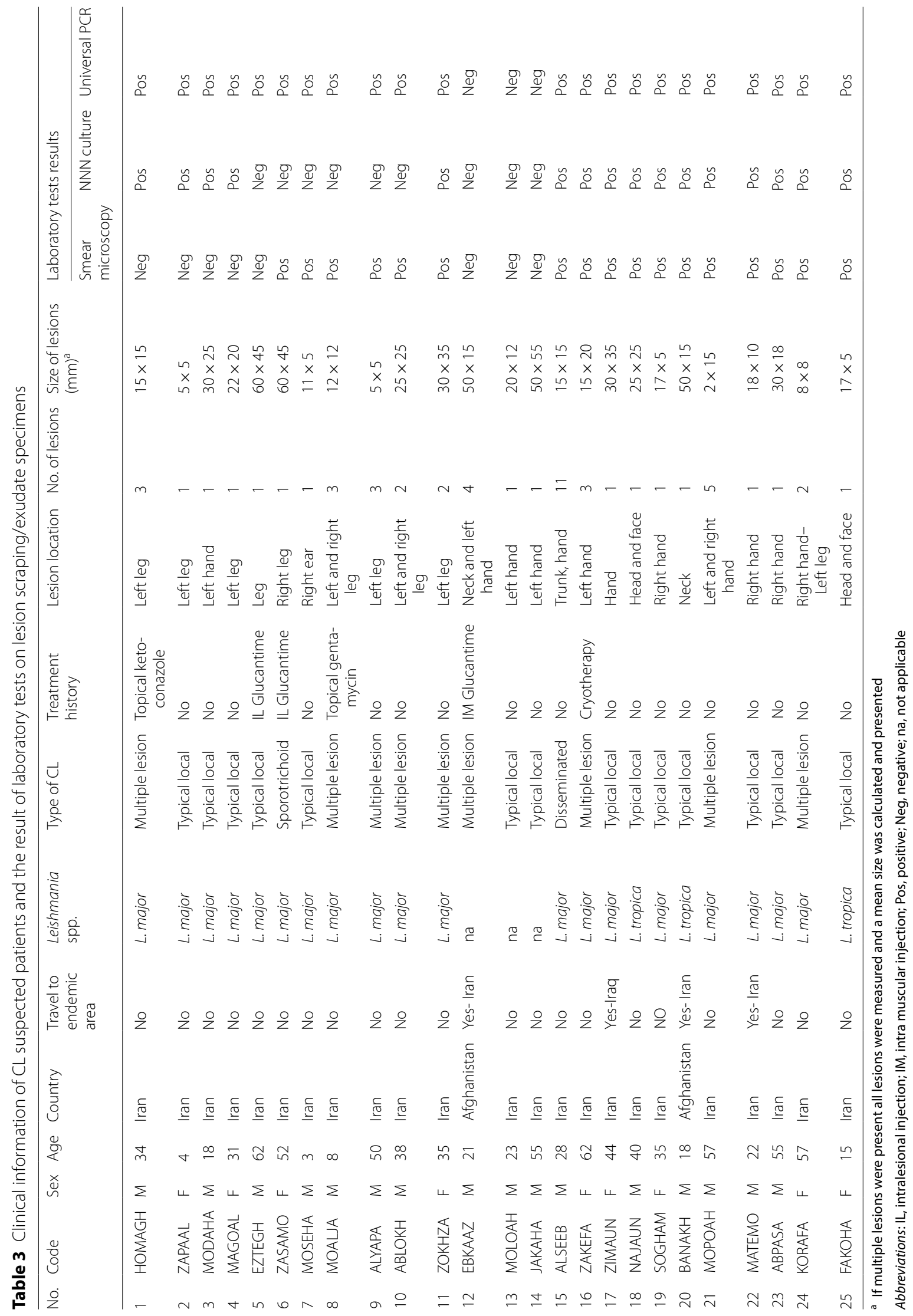


Table 4 The result of universal PCR assay on biopsy samples collected from patients with skin diseases mimic CL

\begin{tabular}{|c|c|c|c|c|c|c|c|c|c|}
\hline No. & Code & Age & Sex & Geographical region & Travel to endemic area & Location & Type & $\begin{array}{l}\text { Gold } \\
\text { standard } \\
\text { result }\end{array}$ & Universal PCR \\
\hline 1 & $\mathrm{KHHA}$ & 65 & $\mathrm{~F}$ & Iran (Kordestan) & No & Right calf & na & Neg & Neg \\
\hline 2 & GOBA & 92 & M & Iran (Rey) & No & Foot toes & na & Neg & Neg \\
\hline 3 & BAMO & 48 & $\mathrm{~F}$ & Iran (Rey) & Yes (Iran: Kermanshah) & Lower abdomen & na & Neg & Neg \\
\hline 4 & ZADO & 58 & $\mathrm{~F}$ & Iran (Karaj) & No & Arm & na & Neg & Neg \\
\hline 5 & HOAJ & 49 & M & Iran (Karaj) & No & Forearm & na & Neg & Neg \\
\hline 6 & FANO & 23 & $\mathrm{~F}$ & Iran (Ghods) & Yes (Iran: Mashhad) & Left foot & na & Neg & Neg \\
\hline 7 & MAHA & 39 & M & Iran (Tehran) & No & Cheek & na & Neg & Neg \\
\hline 8 & ALHA & 69 & M & Iran (Tehran) & No & Forearm & na & Neg & Neg \\
\hline 9 & RAES & 39 & M & Iran (Eslamshahr) & No & Ear & na & Neg & Neg \\
\hline 10 & SOEB & 59 & M & Iran (Ghods) & No & Right and left hand & na & Neg & Neg \\
\hline 11 & $\mathrm{MOHO}$ & 38 & M & Iran (Tehran) & No & Right hand & na & Neg & Neg \\
\hline 12 & RAAH & 16 & M & Iran (Tehran) & No & Right hand & L.major & Pos & Pos \\
\hline 13 & ATSH & 6 & $\mathrm{~F}$ & Iran (Tehran) & Yes (Iran: Aghaliabbas) & Left hand & L. major & Pos & Pos \\
\hline 14 & $\mathrm{ABGH}$ & 27 & M & Iran (Tehran) & No & Head and face & L. tropica & Pos & Pos \\
\hline 15 & FAMO & 20 & $\mathrm{~F}$ & Iran (Tehran) & No & Right leg & & Pos & Pos \\
\hline 16 & EBES & 42 & M & Iran (Tehran) & No & Left hand & L. tropica & Pos & Pos \\
\hline 17 & BIDE & 69 & M & Iran (Eslamshahr) & Yes (Iran: Azerbaijan) & Leg & L. major & Pos & Pos \\
\hline 18 & DAAH & 48 & M & Iran (Mazandaran) & Yes (Iran: Isfahan, Yazd, Kerman) & Arm & L. major & Pos & Pos \\
\hline 19 & FAPI & 3 & M & Iran (Ardabil) & Yes (Iraq: Karbala) & Head and face & L.major & Pos & Pos \\
\hline 20 & YAMO & 42 & M & Iran (Tehran) & Yes (Iran: Bandarabbas) & Trunk & L.major & Pos & Pos \\
\hline 21 & MOFE & 26 & M & Iran (Karaj) & Yes (Iraq: Karbala) & Hand & L.major & Pos & Pos \\
\hline 22 & BEMO & 65 & M & & No & Head and hand & L. tropica & Pos & Pos \\
\hline 23 & MAMA & 40 & $\mathrm{~F}$ & Iran (Tehran) & Yes (Iran: Ardabil) & Right hand & L. major & Pos & Pos \\
\hline 24 & ASMA & 12 & $\mathrm{~F}$ & Iran (Tehran) & Yes (Iran: Isfahan) & Face, hand, leg & L. major & Pos & Pos \\
\hline
\end{tabular}

Abbreviation: na, not applicable; Pos, positive; Neg, negative

Table 5 Performance of conventional parasitology tests and universal PCR in the diagnosis of CL cases

\begin{tabular}{|c|c|c|c|c|c|c|}
\hline Method & Sensitivity (\%) ${ }^{\mathrm{a}}$ & $95 \% \mathrm{Cl}$ & Specificity $(\%)^{b}$ & $95 \% \mathrm{Cl}$ & PPV $(\%)^{c}$ & NPV $(\%)^{d}$ \\
\hline \multicolumn{7}{|l|}{ Conventional parasitology } \\
\hline Stained smear & $77.27(17 / 22)$ & $54.63-92.18$ & $100(3 / 3)$ & $29.24-100$ & $100(17 / 17)$ & $37.50(3 / 8)$ \\
\hline NNN culture & $72.73(16 / 22)$ & $49.78-89.27$ & $100(3 / 3)$ & $29.24-100$ & $100(16 / 16)$ & $33.33(3 / 9)$ \\
\hline \multicolumn{7}{|l|}{ Universal PCR } \\
\hline On lesion scraping/exudate & $100(22 / 22)$ & $84.56-100$ & $100(3 / 3)$ & $29.24-100$ & $100(22 / 22)$ & $100(3 / 3)$ \\
\hline On lesion biopsy & $100(13 / 13)$ & $75.29-100$ & $100(11 / 11)$ & $71.51-100$ & $100(13 / 13)$ & $100(11 / 11)$ \\
\hline
\end{tabular}

${ }^{a}$ No. of true positive/no. of infected persons

b No. of true negative/no. of non-infected persons

c No. of true positive/no. of positive results

${ }^{d}$ No. of true negative/no. of negative results

Abbreviations: $\mathrm{Cl}$, confidence intervals; PPV, positive predictive value; NPV, negative predictive value

less than $78 \%$, while culture and microscopy together improved the overall sensitivity to more than $90 \%$ (21/22 positive samples). In other studies, the sensitivity of conventional parasitological methods in the diagnosis of CL ranged from $\sim 30 \%$ to $\sim 85 \%$ for either smear or culture and were always lower than molecular methods based on PCR [32, 33].

In this study, PCR of the ITS2 target enabled identification of $100 \%$ of the CL patients by analysis of DNA from positive samples including scraping/exudate 
$(25 / 25)$ and biopsy samples (24/24), which included strains of $L$. major and L. tropica. Since neither conventional parasitology nor PCR showed false positives, all the assays were $100 \%$ specific. In support of our approach in selection of the ITS region as an amplification target, previous studies have reported high sensitivity of the ITS2-PCR in diagnosis of CL and visceral leishmaniasis (VL) cases, as compared to microscopic examination [18]. Also, the real-time PCR method for the ITS2 region in Leishmania has been suggested as one of the most sensitive diagnostic tests for identifying parasite load $[34,35]$. In another report, the kDNA PCR showed the highest sensitivity (98.7\%) compared to any other assay, followed by the rRNA ITS PCR (91.0\% sensitivity) [36].

In our study, there were ten discordant results among 25 scraping/exudate samples including four samples with positive culture which were negative by smear examination, and five samples which were positive by microscopy but negative in culture growth. One sample of a CL patient that was negative in both culture and examination by light microscopy, was confirmed positive by the universal PCR. This patient received intralesional Glucantime and the negative result following conventional parasitological approaches might be attributed to disrupted amastigote remnants in lesion specimens. All ten samples which were negative in one or both of parasitological approaches were identified as $L$. major by the universal PCR approach. We were blind of the result of "gold standard" testing on skin lesions suggestive of CL, so the authors were not aware of the cases of CL while testing the universal PCR on samples. False negative results highlight the underestimation of identification of $\mathrm{CL}$ cases which needs to be regarded in clinical management of the disease.

One advantage of PCR-based molecular approaches in diagnosis of infections is that they do not need a viable organism for detection. In some instances, negative culture results might be attributable to fastidious or nonviable parasites in the specimens collected for culture or to contamination of the NNN media. On the other hand, the lack of a positive smear for some of the culture/PCR positive samples might be due to unequal distributions of parasites in the lesion, such that the parasite number in the portion collected for smear preparation was not enough for detection by microscopy. Nevertheless, proper detection of amastigotes requires an experienced microscopist.

With 100\% PPV and NPV by PCR, a positive result from either lesion scraping/exudate or biopsy sample should always be considered a true positive, and a negative test result should always be considered a true negative.
Molecular diagnosis provides improvements in clinical diagnosis of leishmaniasis; however, the selection of the most suitable PCR technique is not always easy. We have validated our PCR on both lesion scraping/exudate and skin biopsy samples. Some developed PCRs did not show enough sensitivity in clinical settings and were recommended only for identification of Leishmania on culture isolates [37]. CL lesions due to L. infantum contain a lower parasitic load than those due to L. tropica or $L$. major and is reportedly more difficult to isolate. Therefore, dermal aspirates of the lesion might not be sufficient for microscopic detection of $L$. infantum infection but it should be suitable for PCR diagnosis [38].

We used culture promastigotes of reference strains to determine LOD. As shown here, the universal PCR could detect as little as $0.1-0.01 \mathrm{pg}$ of Leishmania DNA and shows a higher sensitivity than certain other species- and genus-specific PCRs developed to detect Leishmania species causing CL [29].

Simultaneous co-infection with two species of Leishmania in clinical cases of leishmaniasis is not implausible [39], therefore the possibility of mixed infection of different strains should be regarded in diagnostics approaches. We have examined the possible interference of the presence of DNA from other Leishmania species in the PCR reaction and the efficiency of the universal PCR was not affected by co-infections.

Diagnostic tools are necessary to detect and identify Leishmania species both in endemic areas where different species coexist and in non-endemic areas where imported CL cases occur due to travel and population migration [40]. In this study, CL cases due to L. major or L. tropica were also detected among immigrants of Afghanistan and Iraq, two main immigrant populations who have a long history of living in Iran. Afghanistan is one of the major foci of CL in the world and the capital Kabol is the endemic area with highest incidence rate of ACL in the world, with an estimated annual incidence of 67,500 cases. We used the ITS region of the rRNA gene of Leishmania as a target to develop an affordable, specific, and easy-to-use PCR test to discriminate L. infantum, L. tropica and L. major. This universal PCR assay enables identification the infecting Leishmania species in both lesion exudate and biopsy samples, without any cross-reaction with other skin diseases compatible with CL. It has also the capability to be used as a tool to characterize Leishmania species on culture promastigotes or directly on cryopreserved samples.

\section{Conclusions}

Molecular techniques have significantly improved the diagnosis of CL-suspected patients in endemic areas of leishmaniasis. The presented universal PCR assay can 
be used routinely in diagnosis of suspected CL cases, since the performance of this rDNA-ITS2 PCR to reliably identify $L$. major, $L$. tropica and $L$. infantum is validated on clinical samples. However, additional studies with more clinical samples from areas of CL endemicity in the Old World are needed to evaluate the feasibility of using this universal PCR in clinical settings.

\section{Supplementary information}

Supplementary information accompanies this paper at https://doi. org/10.1186/s13071-020-04261-5.

Additional file 1: Figure S1. The results of electrophoresis of the products of the nested PCR-RFLP based amplification of DNA extracted from Leishmania reference strains before and after enzymatic digestion with $\mathrm{Mn} / \mathrm{l}$. Digestion was performed by adding $5 \mathrm{U}$ of $\mathrm{Mn} / \mathrm{l}$ restriction enzyme to a $13 \mu \mathrm{l}$ aliquot of the nested PCR product for $3 \mathrm{~h}$ at $37^{\circ} \mathrm{C}$ and the products were visualized on $2.5 \%$ agarose gel electrophoresis. Lanes 1-3 L. major (245 bp), L. tropica (99 bp) and L. infantum (200 bp) before digestion, respectively. Lane 4: products of $L$. major (106, 73 and 44-bp fragments); Lane 5: products of L. tropica (75, 67 and 19-bp fragments); Lane 6: products of $L$. infantum (127, 33 and 30-bp fragments) after enzymatic digestion. Lane 7: negative control. Lane L: 100 bp ladder.

Additional file 2: Alignment S1. Nucleotide sequence alignment of the rDNA-ITS region of CL-causing species of Leishmania. Leishmania sequences generated by ITS2-PCR using universal primers UNIL-IR-P and UNIL-IR-M. Sequences from three different strains of CL-causing Leishmania spp. are aligned against L. major (Friedlin strain). The primer pair position and flanking sequences are shown. The yellow highlighted positions indicate the start and end of 5.85 and green highlighted position indicates initiation of LSUa of 285 fragments. The primer binding regions are shown in rectangles.

\section{Abbreviations}

CL: cutaneous leishmaniasis; $A C L$ : anthroponotic CL; ZCL: zoonotic CL; PCR: polymerase chain reaction; ITS: internal transcribed spacer; ETS: external transcribed spacer; NNN: Novy-MacNeal-Nicolle; NTC: non-template negative control; LOD: limit of detection; kDNA: kinetoplast DNA; VL: visceral leishmaniasis.

\section{Acknowledgements}

We would like to thank Ms. R. Davoudian and Ms. S. Mohammadi from the Pasteur Institute of Iran, and Mrs. F. Abedi Astaneh from Qom University of Medical Sciences, for their kind cooperation in this study. We would also like to thank Dr. S. Ajdari, Department of Immunology, Pasteur Institute of Iran, for providing us with some reference strains.

\section{Authors' contributions \\ MNR designed the study, analysed the data and wrote the manuscript. FD performed the PCR tests, contributed to data collection and sampling. MF contributed to sampling and performing parasitological tests. MA performed biopsy collection and patients' information analysis. PP contributed to experi- mental design and sample collection. All authors read and approved the final manuscript.}

\section{Funding}

This study is supported by Pasteur Institute of Iran. The Institute had no role in the design of the study and collection, analysis, and interpretation of data and in writing the manuscript.

\section{Availability of data and materials}

Data supporting the conclusions of this article are included within the article and its additional files. The datasets used and/or analysed during the present study are available from the corresponding author on reasonable request.

\section{Ethics approval and consent to participate}

The study was approved by the Ethical Committee of Pasteur Institute of Iran, Tehran, Iran. All procedures were in accordance with the ethical standards of human experimentation of 1964 Declaration of Helsinki and its later amendments (World Medical Association, 64th WMA General Assembly, Fortaleza, Brazil, October 2013). The same samples which were taken during routine diagnostics were used, however, informed consent was obtained from each volunteer participated in the study.

\section{Consent for publication}

Not applicable.

\section{Competing interests}

The authors declare that they have no competing interests.

\section{Author details}

${ }^{1}$ Laboratory of Host-Parasite Interactions, Department of Parasitology, Pasteur Institute of Iran, Tehran, Iran. ${ }^{2}$ Qom University of Medical Sciences, Qom, Iran. ${ }^{3}$ Molecular Systematics Laboratory, Department of Parasitology, Pasteur Institute of Iran, Tehran, Iran.

Received: 8 January 2020 Accepted: 23 July 2020

Published online: 27 August 2020

\section{References}

1. Meireles CB, Maia LC, Soares GC, Teodoro IPP, Gadelha M, da Silva CGL, et al. Atypical presentations of cutaneous leishmaniasis: a systematic review. Acta Trop. 2017;172:240-54.

2. Khamesipour A, Nateghi Rostami M, Tasbihi M, Miramin Mohammadi A, Shahrestani T, Sarrafnejad A, et al. Phenotyping of circulating CD8(+) T cell subsets in human cutaneous leishmaniasis. Microbes Infect. 2012;14:702-11.

3. Nateghi Rostami M, Seyyedan Jasbi E, Khamesipour A, Mohammadi AM Tumour necrosis factor-alpha (TNF-alpha) and its soluble receptor type 1 (sTNFR I) in human active and healed leishmaniases. Parasite Immunol. 2016;38:255-60.

4. Banuls AL, Bastien P, Pomares C, Arevalo J, Fisa R, Hide M. Clinical pleiomorphism in human leishmaniases, with special mention of asymptomatic infection. Clin Microbiol Infect. 2011;17:1451-61.

5. Nateghi Rostami M, Saghafipour A, Vesali E. A newly emerged cutaneous leishmaniasis focus in central Iran. Int J Infect Dis. 2013;17:e1198-206.

6. Romero GA, Boelaert M. Control of visceral leishmaniasis in latin americaa systematic review. PLoS Negl Trop Dis. 2010;4:e584.

7. El Hassan AM, Khalil EA, Elamin WM, El Hassan LA, Ahmed ME, Musa AM. Misdiagnosis and mistreatment of post-kala-azar dermal leishmaniasis. Case Rep Med. 2013;2013:351579.

8. Tashakori M, Kuhls K, Al-Jawabreh A, Mauricio IL, Schonian G, Farajnia $S$, et al. Leishmania major: genetic heterogeneity of Iranian isolates by single-strand conformation polymorphism and sequence analysis of ribosomal DNA internal transcribed spacer. Acta Trop. 2006;98:52-8.

9. Mahmoudzadeh-Niknam H, Ajdary S, Riazi-Rad F, Mirzadegan E, Rezaeian A, Khaze $V$, et al. Molecular epidemiology of cutaneous leishmaniasis and heterogeneity of Leishmania major strains in Iran. Trop Med Int Health. 2012;17:1335-44.

10. Gabriel A, Valerio-Bolas A, Palma-Marques J, Mourata-Goncalves P, Ruas P, Dias-Guerreiro T, et al. Cutaneous leishmaniasis: the complexity of host's effective immune response against a polymorphic parasitic disease. J Immunol Res. 2019;2019:2603730.

11. Ricciardi A, Ndao M. Diagnosis of parasitic infections: what's going on? J Biomol Screen. 2015;20:6-21.

12. Al-Jawabreh A, Dumaidi K, Ereqat S, Nasereddin A, Azmi K, Al-Jawabreh H, et al. A comparison of the efficiency of three sampling methods for use in the molecular and conventional diagnosis of cutaneous leishmaniasis. Acta Trop. 2018;182:173-7.

13. Merino-Espinosa G, Rodriguez-Granger J, Morillas-Marquez F, Tercedor J, Corpas-Lopez V, Chiheb S, et al. Comparison of PCR-based methods for the diagnosis of cutaneous leishmaniasis in two different epidemiological scenarios: Spain and Morocco. J Eur Acad Dermatol Venereol. 2018;32:1999-2003. 
14. Mouttaki T, Morales-Yuste M, Merino-Espinosa G, Chiheb S, Fellah H, Martin-Sanchez J, et al. Molecular diagnosis of cutaneous leishmaniasis and identification of the causative Leishmania species in Morocco by using three PCR-based assays. Parasit Vectors. 2014;7:420.

15. Moreira OC, Yadon ZE, Cupolillo E. The applicability of real-time PCR in the diagnostic of cutaneous leishmaniasis and parasite quantification for clinical management: current status and perspectives. Acta Trop. 2018;184:29-37.

16. Araujo-Pereira T, Pita-Pereira D, Moreira RB, Silva-Galdino T, Duarte MPO, Brazil RP, et al. Molecular diagnosis of cutaneous leishmaniasis in an endemic area of Acre State in the Amazonian Region of Brazil. Rev Soc Bras Med Trop. 2018;51:376-81.

17. Asfaram S, Fakhar M, Mirani N, Derakhshani-Niya M, Valadan R, Ziaei Hezarjaribi $\mathrm{H}$, et al. HRM-PCR is an accurate and sensitive technique for the diagnosis of cutaneous leishmaniasis as compared with conventional PCR. Acta Parasitol. 2020;65:310-6.

18. Koltas IS, Eroglu F, Uzun S, Alabaz D. A comparative analysis of different molecular targets using PCR for diagnosis of old world leishmaniasis. Exp Parasitol. 2016;164:43-8.

19. Azmi K, Nasereddin A, Ereqat S, Schnur L, Schonian G, Abdeen Z. Methods incorporating a polymerase chain reaction and restriction fragment length polymorphism and their use as a 'gold standard' in diagnosing Old World cutaneous leishmaniasis. Diag Microbiol Infect Dis. 2011;71:151-5.

20. de Almeida ME, Steurer FJ, Koru O, Herwaldt BL, Pieniazek NJ, da Silva AJ. Identification of Leishmania spp. by molecular amplification and DNA sequencing analysis of a fragment of rRNA internal transcribed spacer 2 . $J$ Clin Microbiol. 2011;49:3143-9.

21. Martinez-Calvillo S, Sunkin SM, Yan S, Fox M, Stuart K, Myler PJ. Genomic organization and functional characterization of the Leishmania major Friedlin ribosomal RNA gene locus. Mol Biochem Parasitol. 2001;116:147-57.

22. Martinez-Calvillo S, Florencio-Martinez LE, Nepomuceno-Mejia T. Nucleolar structure and function in trypanosomatid protozoa. Cells. 2019;8:421.

23. Leon W, Fouts DL, Manning J. Sequence arrangement of the 165 and 265 rRNA genes in the pathogenic haemoflagellate Leishmania donovani. Nucleic Acids Res. 1978;5:491-504.

24. Inga R, De Doncker S, Gomez J, Lopez M, Garcia R, Le Ray D, et al. Relation between variation in copy number of ribosomal RNA encoding genes and size of harbouring chromosomes in Leishmania of subgenus Viannia. Mol Biochem Parasitol. 1998;92:219-28.

25. Nateghi Rostami M, Keshavarz Valian H, Eskandari SE, Miramin Mohammadi A, Shahrestani ST, Sarraf-Nejad A, et al. Differential in vitro CD4+/ CD8+ T-cell response to live vs killed Leishmania major. Parasite Immunol. 2010;32:101-10.

26. Kumar S, Stecher G, Tamura K. MEGA7: Molecular Evolutionary Genetics Analysis version 7.0 for bigger datasets. Mol Biol Evol. 2016;33:1870-4

27. Ceccarelli M, Galluzzi L, Diotallevi A, Andreoni F, Fowler H, Petersen C, et al. The use of kDNA minicircle subclass relative abundance to differentiate between Leishmania (L.) infantum and Leishmania (L.) amazonensis. Parasit Vectors. 2017;10:239.

28. Akhavan AA, Yaghoobi-Ershadi MR, Khamesipour A, Mirhendi H, Alimohammadian MH, Rassi Y, et al. Dynamics of Leishmania infection rates in Rhombomys opimus (Rodentia: Gerbillinae) population of an endemic focus of zoonotic cutaneous leishmaniasis in Iran. Bull Soc Pathol Exot. 2010;103:84-9.

29. Odiwuor SO, Saad AA, De Doncker S, Maes I, Laurent T, El Safi S, et al. Universal PCR assays for the differential detection of all Old World Leishmania species. Eur J Clin Microbiol Infect Dis. 2011;30:209-18.

30. Toz SO, Culha G, Zeyrek FY, Ertabaklar H, Alkan MZ, Vardarli AT, et al. A realtime ITS1-PCR based method in the diagnosis and species identification of Leishmania parasite from human and dog clinical samples in Turkey. PLoS Negl Trop Dis. 2013;7:e2205.

31. Ramezany M, Sharifi I, Babaei Z, Ghasemi Nejad Almani P, Heshmatkhah A, Keyhani A, et al. Geographical distribution and molecular characterization for cutaneous leishmaniasis species by sequencing and phylogenetic analyses of kDNA and ITS1 loci markers in south-eastern Iran. Pathog Glob Health. 2018;112:132-41.

32. Boggild AK, Valencia BM, Espinosa D, Veland N, Ramos AP, Arevalo J, et al. Detection and species identification of Leishmania DNA from filter paper lesion impressions for patients with American cutaneous leishmaniasis. Clin Infect Dis. 2010;50:e1-6.

33. Rasti S, Ghorbanzadeh B, Kheirandish F, Mousavi SG, Pirozmand A, Hooshyar $\mathrm{H}$, et al. Comparison of molecular, microscopic, and culture methods for diagnosis of cutaneous leishmaniasis. J Clin Lab Anal. 2016;30:610-5.

34. Fekri Soofi Abadi M, Dabiri S, Fotouhi Ardakani R, Fani Malaki L, Amirpoor Rostami S, Ziasistani M, et al. Design and validation of real-time PCR: quantitative diagnosis of common Leishmania species in Iran. Arch Iran Med. 2016;19:496-501.

35. de Almeida ME, Koru O, Steurer F, Herwaldt BL, da Silva AJ. Detection and differentiation of Leishmania spp. in clinical specimens by use of a SYBR green-based real-time PCR assay. J Clin Microbiol. 2017;55:281-90.

36. Bensoussan E, Nasereddin A, Jonas F, Schnur LF, Jaffe CL. Comparison of PCR assays for diagnosis of cutaneous leishmaniasis. J Clin Microbiol. 2006:44:1435-9.

37. Laurent T, Van der Auwera G, Hide M, Mertens P, Quispe-Tintaya W, Deborggraeve S, et al. Identification of Old World Leishmania spp. by specific polymerase chain reaction amplification of cysteine proteinase $B$ genes and rapid dipstick detection. Diag Microbiol Infect Dis. 2009;63:173-81.

38. Martin-Sanchez J, Pineda JA, Andreu-Lopez M, Delgado J, Macias J, De La Rosa R, et al. The high sensitivity of a PCR-ELISA in the diagnosis of cutaneous and visceral leishmaniasis caused by Leishmania infantum. Ann Trop Med Parasitol. 2002;96:669-77.

39. Babiker AM, Ravagnan S, Fusaro A, Hassan MM, Bakheit SM, Mukhtar MM, et al. Concomitant infection with Leishmania donovani and L. major in single ulcers of cutaneous leishmaniasis patients from Sudan. J Trop Med. 2014;2014:170859.

40. Perez-Ayala A, Norman F, Perez-Molina JA, Herrero JM, Monge B, LopezVelez R. Imported leishmaniasis: a heterogeneous group of diseases. J Travel Med. 2009;16:395-401.

\section{Publisher's Note}

Springer Nature remains neutral with regard to jurisdictional claims in published maps and institutional affiliations.

Ready to submit your research? Choose BMC and benefit from

- fast, convenient online submission

- thorough peer review by experienced researchers in your field

- rapid publication on acceptance

- support for research data, including large and complex data types

- gold Open Access which fosters wider collaboration and increased citations

- maximum visibility for your research: over 100M website views per year

At BMC, research is always in progress.

Learn more biomedcentral.com/submissions 